\title{
DOS ENTREMESES «AUDITIVOS»Y SUS NIVELES: HACIA UN METATEATRO VISUAL
}

\author{
ADRIÁN FERNÁNDEZ \\ Université de Fribourg \\ adrian.fernandez@unifr.ch
}

\section{NIVELES DRAMÁTICOS Y METATEATRO}

$\square$ 1 corpus entremesil ${ }^{1}$ del Siglo de Oro suele destacarse por su vertiente más tipológica - reproducciones sociológicas y figuras caricaturales (Alguacil, Estudiante, Bobo, Sacristán, Alcalde, etc.)—y por su profusión lingüística (jergas y refranes), en un propósito cómico que ha dejado de lado consideraciones como la vertiente estructural. Sin embargo, son consabidas algunas construcciones particulares en obras como el Retablo de las maravillas o Las Alforjas. Aun así, a menudo se han relegado a un segundo plano en beneficio de otros enfoques temáticos o contextuales.

Se pueden mencionar, a nuestro entender, algunas funciones más que participan de la concepción y definición del género entremesil si lo consideramos dentro de la «fiesta teatral» (Huerta Calvo 2008: 57), como una parte de un conjunto. Así pues, son cuatro las que nos interesan: temporizadora, equilibradora, promocional y especular:

1. Bien conocida es la voluntad temporizadora con la inserción de obras cortas en la representación mayor, sea para facilitar el cambio de ropa o instrumentos, sea para darle descanso al público. En suma, el entremés suspende el desarrollo temporal del argumento de la comedia principal ${ }^{2}$.

Con respecto al entremés, véase Asensio (1971), Martínez López (1997) o Huerta Calvo (2001; 2008), así como la colección de Cotarelo y Mori (2000), con un gran elenco de obras breves del Siglo de Oro.

2 Esta función es asimilable al nexo llamado «suspensión» que define García Barrientos (2007: 91): «Consiste estrictamente en una detención del tiempo ficticio de la fábula, pero sin interrumpir el curso del tiempo real de la escenificación. [...] La solución parece ser el carácter relativo de 
2. La función equilibradora del entremés tiene que ver con la estética de la variatio que Lope de Vega ya mencionaba en su Arte Nuevo, y que se traduce en la construcción dramática por el equilibrio entre lo serio y lo cómico. En este sentido, el entremés que se inserta en la obra mayor, de asunto serio en general, debe ser profundamente cómico para contrastar con la pieza principal: no solo cumple con un requisito de tiempo, sino también con una finalidad de equilibrio del conjunto dramático.

3. Por promocional se entiende la posibilidad para un actor secundario de la obra principal de interpretar un papel más determinante en el entremés y ser valorado por el público. A su vez, podía servir para que un actor que tenía un papel serio enseñara al público sus cualidades como cómico, como en el caso de Juan Rana (Huerta Calvo 2008: 47).

4. La función de mise en abyme remite a los paralelismos estructurales con la obra mayor, puesto que ambas son representaciones teatrales. Con o sin rasgos temáticos en común, la relación especular entre obra principal y obra intercalada existe ${ }^{3}$ : se trata, dentro de una representación mayor en la que se presenta a un público la historia de unos personajes interpretados por actores sobre un escenario, de otra representación más breve en la que el mismo público recibe otra historia por parte de los mismos actores (o no) sobre el mismo escenario. Así pues, podemos hablar de mise en abyme en este tipo de relaciones obra cuadro/obra encuadrada.

Si las tres primeras funciones son de carácter más bien utilitario, la última señala un recurso estético que ha dado lugar a otros juegos especulares. Más allá de estos apuntes que sirven ante todo para valorar más detenidamente el marco estructural bajo el cual se puede estudiar el entremés, nos interesa sobre todo la consecuencia metateatral de tales juegos especulares.

El metateatro es un término «comodín» para definir las estructuras particulares de ciertas obras que presentan desdoblamientos de niveles y fenómenos de ruptura de la cuarta pared. En efecto, esta configuración aparece en varios entremeses, a menudo con el objetivo de fomentar la burla. Además de los ya mencionados Retablo de las maravillas (tanto de Cervantes como de Quiñones de Benavente) y Las Alforjas del mismo Quiñones, se podrían incluir otros entremeses: Escandarbey de Francisco Bernardo de Quirós, La burla más sazonada de Luis Vélez de Guevara, y Los refranes del viejo celoso atribuido a Quevedo. El análisis detenido

este nexo, como ya vimos en el resumen: su contenido deberá corresponder a "otro" nivel, a otra historia, incluso a otra clase de espectáculo.»

3 «Le mot abyme est ici un terminus technicus. [...] est mis en abyme toute enclave entretenant une relation de similitude avec l'œuvre qui la contient» (Dällenbach 1977: 17-18). 
de tales fenómenos en tres de estas obras puede servir para completar las aportaciones teóricas sobre el metateatro y reconsiderar esta denominación para ciertas obras dramáticas.

Desde la creación del término por Lionel Abel (1963), cuya teoría se aproximaba más bien a un alto grado de teatralidad en una obra (como sería el caso en La vida es sueño), el metateatro - y nombres afines como el «teatro dentro del teatro»- ha recibido varias contribuciones, entre las cuales destacaremos para nuestra reflexión a Forestier (1981), Hornby (1986), García Barrientos (2007) y Herzog (2013). De forma general, el metateatro es un desdoblamiento. Se trata de unos signos que se refieren a sí mismos, un movimiento de autorreferencia dentro de una forma bien definida. Basándose en las teorías diegéticas de Genette (1972), García Barrientos define tres planos dramáticos aplicables a las representaciones teatrales:

Así el nivel extradramático equivale al plano escénico (real, representante), el nivel intradramático al plano diegético (ficticio, representado) y el metadramático al drama dentro del drama. Y la lógica de los niveles se puede formular así: la escenificación de un drama primario es por definición extradramática, como la escenificación de un drama secundario (metadrama) es por definición intradramática, etc. (García Barrientos 2007: 231)

Además, divide el nivel metadramático en tres categorías: 1) La metadiégesis: se trata de una «fábula secundaria, argumento de segundo grado o historia de otra historia»; 2) El metadrama: se denomina así la historia secundaria en cierto sentido teatralizada, escenificada, que «no se presenta como producid[a] por una puesta en escena, sino por un sueño, un recuerdo, la acción verbal de un "narrador", etc.»; y 3) El metateatro: es, sencillamente, lo que se suele llamar «teatro dentro del teatro». En otras palabras, «implica una puesta en escena teatral dentro de otra (actor real representando a un actor teatral representando a un personaje dramático)» (García Barrientos 2007: 232). En suma, si una historia secundaria es contada, se trata de metadiégesis. Si esta es representada mediante un sueño o un recuerdo, llega al plano metadramático. Y si se le añade una forma teatral, desdoblando así los componentes teatrales - siendo por tanto una mise en abyme de la representación principal en cuanto a su estructura-, estamos en el metateatro.

La metadiégesis es fácilmente reconocible, pero la distinción entre metadrama y metateatro supone ciertos problemas que a menudo encontramos en la lectura de textos dramáticos. Es imprescindible comprender que el metateatro es una forma de metadrama más concreta porque contiene elementos claramente teatrales que se duplican: los componentes son desdoblados, creando así un tiempo t dentro del tiempo $\mathrm{T}$, un espacio e dentro del espacio $\mathrm{E}$, un argumento a como componente de 
$\mathrm{A}^{4}, \mathrm{o} / \mathrm{y}$ un papel $\mathrm{p}$ interpretado por un papel $\mathrm{P}^{5}$. De este modo, la representación insertada se hace eco de la estructura de la obra principal (mise en abyme formal), $\mathrm{y}$ a veces al asunto de esta (mise en abyme formal y temática). Se trata de una forma de visión doble, que Hornby ve como fuente del metateatro: «this 'seeing double' is the true source of the significance of metadrama» (Hornby 1986: 32) ${ }^{6}$. Aquí aparece la diferencia más notable con el concepto abeliano de metateatro: la representación de un personaje sujeto al topos del Theatrum mundi actuará como si él mismo fuese un papel en el universo, y Dios su espectador. Se trata de un extremo en la teatralización de la vida, pero no llega a ser metateatro, puesto que no ofrece desdoblamiento de las instancias dentro de la representación. En suma, el metateatro habla de sí mismo, mientras que el concepto abeliano se refiere a obras que no hablan de sí mismas, sino de la vida?

Quizás el desdoblamiento más importante sea el del público . Es el caso de la parábasis, fenómeno según el cual un personaje finge comunicar con el público y crea una estancia idealizada a la cual se dirige, de modo que lo desdobla. De todos modos, la componente especular es fundamental, pues remite a los ecos entre niveles dramáticos. Con esto podemos convenir que el metateatro es, en definitiva, una duplicación de signos llevada a la escena mediante la mise en abyme. En otras palabras, hay metateatro cuando al menos un elemento dramático (escenario, personaje, público...) se repite dentro de la representación, creando así un juego de espejos explícito. No obstante, su aplicación resulta problemática cuando una de esas instancias está ausente en la escenificación, pero se corporiza mediante la palabra.

\section{PALAbra RePResentativa y CREACión VISUAL}

Dentro de las funciones de la palabra destacadas por Ingarden, la más interesante en cuanto a creación de niveles es la representativa:

$4 \quad$ Debe tenerse en cuenta que la presencia del argumento metateatral puede no influir en la trama. El Teatro dentro del Teatro también posee una función de mera distracción (Forestier 1981: 14).

5 Este desdoblamiento del papel implica también el posible juego con las instancias teatrales (autor/director, actores y público). Sucede con Hamlet, encarnación del público al asistir a la obra insertada.

6 Hornby usa «metadrama» con el sentido que nosotros le damos a «metateatro»: «Briefly, metadrama can be defined as drama about drama; it occurs whenever the subject of a play turns out to be, in some sense, drama itself» (Hornby 1986: 31).

7 «Con metateatro, proponemos aludir a un proceso significativo más amplio, en el que caben todas las estrategias semánticas a través de las cuales el teatro habla de sí mismo» (Herzog 2013: 57).

8 «Il y a théâtre dans le théâtre à partir du moment où un au moins des acteurs de la pièce-cadre se transforme en spectateur» (Forestier 1981: 11). 
Este modo de representación puede realizarse de una manera puramente conceptual $[\ldots]$ o de manera que las realidades tratadas accedan a la representación bajo forma de imágenes sensibles evocadas globalmente. Esta función representativa no juega entonces más que un papel de apoyo en la constitución del universo teatral: en efecto, es un elemento visual, proporcionado por las realidades mostradas en escena (es decir, solamente en el espacio representado), que asume el rol esencial en este dominio (Ingarden 1997: 160).

En el corpus entremesil, la brevedad obliga a coger ciertos atajos dramáticos a la hora de elaborar un segundo nivel. En esta perspectiva, el verbo se define como la vía real para establecer elementos necesarios para la comprensión de la trama, como en Los refranes del viejo celoso ${ }^{9}$. Este entremés, que sigue el esquema típico de un paso de Lope de Rueda (un viejo cornudo burlado por los amantes con el final «a palos»), desarrolla un juego entre niveles particularmente interesante para la reflexión sobre las funciones de la palabra. En efecto, representa la historia de Rincón y Justa, la cual está casada con un aficionado de refranes. En reacción a las quejas de su amada, el joven decide burlarse del Vejete y lo hechiza: cada vez que dirá un refrán, saldrá el personaje proverbial a la escena para criticarlo ${ }^{10}$. Estos personajes forman un tribunal que dicta la sentencia correspondiente al final a porrazos sobre el Vejete.

El segundo nivel se crea en el momento del hechizo, haciendo de la magia la promotora del desdoblamiento escénico. Todo comienza con la aparición de un Rincón disfrazado «con botarga colorada, y un cohete encendido en la mano» (Refranes: 123) en una clara asimilación al folklore carnavalesco y a la figura del bufón. A partir de ahí, se erige en alter ego del autor: mientras el escritor real es el creador del nivel intradramático, el mago Rincón hace el papel de director del segundo plano metadramático. La magia justifica así la llegada de los personajes proverbiales: «[RINCóN] Viejo clueco, viejo clueco, / no digas que no te aviso / que de la selva encantada / un mágico había salido, / y dentro della te ha puesto / sin mula ni sin borrico» (Refranes: vv. 98-103). Este pasaje es clave en el desarrollo de un nivel secundario, porque se habla de una «selva encantada» ${ }^{11}$ para el Vejete. La realidad intradramática se vuelca hacia un universo mágico de segundo grado donde van a aparecer los personajes citados por el burlado, y será recordado a lo largo del entremés «¿Qué encantam[i]entos son éstos?» (Refranes: v. 172). A su

$9 \quad$ El entremés (que abreviaremos Refranes) es de atribución dudosa a Quevedo (García Valdés 2005), y se ha señalado a Quiñones de Benavente como posible autor (Bergmann 1975).

10 El tema de la corporización paremiológica no es original: ya aparece en El sueño de la muerte de Quevedo (aparecen los mismos personajes salvo Maricastaña) y en el entremés Las sombras, también de atribución dudosa a Quevedo.

11 La magia también es un recurso fundamental en Las Alforjas de Quiñones de Benavente, así como en otros entremeses donde incluso el Diablo se hace con el protagonismo del hechizo (como sucede posteriormente en los sainetes de Ramón de la Cruz con El diablo, autor aburrido). 
vez, el propio Vejete se va adentrando cada vez más en el segundo plano. En efecto, hasta la aparición de la dueña Quintañona, no hay diálogo entre los personajes proverbiales y él. Quintañona es la primera en interactuar con él y permite al universo mágico beneficiar de un anclaje más profundo: no son solamente apariciones, pues hablan con el personaje de la realidad intradramática. Los niveles se relacionan hasta que se invierte el orden del mundo y el Vejete pasa a ser el extraño en medio del tablado de un tribunal construido por los propios personajes proverbiales. La comparación entre situación inicial y final es reveladora: al principio, todos son seres «reales» (Justa, Rincón y el Vejete). Con la creación del segundo nivel y la salida de Calaínos, los amantes se escapan y dejan al Vejete solo en medio del universo mágico. Los «fantasmas» de los refranes cobran tal sustancia que dialogan con el marido burlado y terminan por condenarlo a la sentencia de los palos. Así pues, el final del entremés está anclado totalmente en el segundo nivel, como señalado por la última aparición de Justa en la representación. Asimilada al personaje proverbial Marta, el Vejete las confunde e indica su pérdida definitiva en el segundo nivel: «[VeJETE:] ¿No es mi mujer ésta? Justa, / ¿en Marta te has convertido?» (Refranes: vv. 220-221).

La primera constatación sobre Los refranes del viejo celoso es la ausencia de desdoblamiento de los protagonistas. En efecto, los personajes proverbiales no son representados por seres del plano intradramático, es decir que Rincón no hace el papel de Calaínos o del Rey Perico ${ }^{12}$. El desdoblamiento, tan característico del metateatro, se produce a través de la creación de un segundo nivel que no desdobla a los personajes, sino únicamente el espacio. Hay dos escenarios: el intradramático y el de la selva encantada. Este último es propio del universo onírico, mágico. Por lo que se trata de un nivel metadramático que no llega a ser metateatral por la ausencia de estancias teatrales concretas.

La función de la palabra en la obra cobra sentido a partir del telón mágico preestablecido por uno de los personajes. Podemos destacar tres características esenciales para la creación del segundo nivel: 1. La introducción de un ingenioso (Rincón) en oposición a otras figuras limitadas intelectualmente; 2. La consolidación contextual mediante recursos oníricos, mágicos o teatrales que legitiman las construcciones posteriores; y 3 . La creación, aquí verbal con la paremia, como aliciente del plan mágico. Sin embargo, la ausencia de ecos puramente teatrales impide que la dimensión metadramática se convierta en metateatral. Eso sí, es una clara muestra de la necesidad de la palabra en la construcción de la burla. Por lo tanto, es interesante detenernos en una obra que desdobla las instancias teatrales gracias, justamente, a la función representativa definida por Ingarden.

12 La confusión del Vejete con Justa puede ser una excepción, si la proverbial Marta es interpretada por la actora que se encarga inicialmente del papel de Justa. 
El efecto producido por la palabra es muy similar en el Retablo de las maravillas. La historia de un retablo encantado viene de una larga corriente de juegos y embustes. Recordemos la trama: un grupo de personas se enfrenta al embuste del retablo. Mediante una ilusión, los protagonistas (Chanfalla y Chirinos en la versión de Cervantes; Pilonga en la de Quiñones) ${ }^{13}$ ridiculizan al público, quien debe someterse a sus creaciones por culpa de la presión social. El Retablo A sigue más estrictamente los tres puntos establecidos con el entremés anterior: Chanfalla y Chirinos son los autores del artificio, con un telón y un discurso que describe las apariciones fantasmagóricas. Van a justificar esta construcción a través de un comentario etiológico sobre el retablo, creado por un sabio llamado Tontonelo (con ironía etimológica). El elemento que mantiene la ilusión es la condición formulada por los ingeniosos: las apariciones no pueden ser percibidas por impuros de sangre o bastardos. El telón de la presión social se establece: por miedo a lo que se pueda contar en el pueblo, todos deben fingir que ven efectivamente lo que se dice que ocurre ${ }^{14}$. Quiñones de Benavente se centra únicamente en los cornudos e infieles, sin que cambie el mecanismo del embuste, puesto que todo reposa en la voluntad de mantener la apariencia. Además, la configuración mágica del retablo es eludida.

Con la representación del embuste comienza el juego metateatral propiamente dicho. Chanfalla, bajo el nombre de Montiel, describe fenómenos extraordinarios que suceden en el retablo: la salida de Sansón, el toro de Salamanca, una manada de ratones, el agua mágica, dos docenas de leones y osos, y una doncella bailarina llamada Herodías. En la versión de Quiñones aparecen solamente el toro y una corriente de agua del Nilo. Mientras los espectadores se despistan, demasiado ocupados en fingir, los burladores los roban. Concretamente, la existencia escénica del retablo se inicia con la puesta en escena del decorado que sirve de trasfondo: el público intradramático sentado, una manta y, lo más importante, la presencia de Chanfalla y Chirinos, cuyas voces dan vida a la obra insertada. La acción, por consiguiente, se termina cuando se descuelga la manta, dando fin a la representación. El texto de Quiñones es más elíptico: enfoca a una víctima en particular (el Alcalde) aunque sea más preciso en cuanto a la interacción entre los personajes, por lo que no encontramos indicaciones escénicas relativas a la construcción del decorado metadramático. Se completa todo - en ambos entremeses- con los enunciados performativos de Chanfalla y Pilonga (Retablo A: 227) ${ }^{15}$ :

13 Nos referiremos al retablo cervantino como Retablo $A$, y al de Quiñones de Benavente como Retablo $B$.

14 La limitación intelectual de las víctimas contribuye al artificio, con recursos como la parodia del lenguaje culto que denuncia su poca cultura o la etimología cómica de algunos personajes (como Juan Castrado).

15 Como lo señala Spadaccini (Cervantes 1990: 227), la fórmula es similar a la de un conjuro. 
Chanfalla. ¡Atención, señores, que comienzo! -iOh tú, quien quiera que fuiste, que fabricaste este Retablo con tan maravilloso artificio, que alcanzó el renombre de las Maravillas : por la virtud que en él se encierra, te conjuro, apremio y mando que luego incontinenti muestres a estos señores algunas de las tus maravillosas maravillas, para que se regocijen y tomen placer sin escándalo alguno!

A partir de ahí, las palabras de los protagonistas van a convertirse en imágenes que salen del retablo y afectan supuestamente a los espectadores. El núcleo oscila entre realidad y ficción, más concretamente entre plano intra y metadramático. Por un lado, Chanfalla y Pilonga cuentan los acontecimientos y crean unas imágenes que no son percibidas por nadie ${ }^{16}$. Por otro lado, las víctimas fingen verlas. El efecto cómico proviene del desfase entre sus distintos comportamientos y sus desconciertos. Estos se ven con los apartes que aparecen sobre todo en el Retablo $B$, ya que es el que más valoriza el segundo aspecto (los vv. 220-233 son un claro ejemplo de este doble juego ${ }^{17}$ ). Al culminar la representación, la confusión entre realidad y ficción es total. Chanfalla no logra convencerlos de que Furrier (que acaba de entrar en escena) no es el fruto de Tontonelo. La incomprensión de Furrier señala la necesidad de instaurar un cuadro propicio para la burla. Como él no fue sometido a la preparación psicológica (de hecho su rango de soldado quizás lo libere de preocupaciones de apariencias sociales), no finge ver las creaciones del retablo y eso implica las sospechas de los aldeanos, quienes terminan acusándolo de ser un impuro y provocan una pelea, el final a palos. Quiñones no concluye el conflicto de la misma forma. Con el río Nilo, las víctimas se quitan las capas para nadar y Pilonga las roba mientras ellos fingen. Al percatarse del robo, se termina la ilusión. Podemos decir, en este sentido, que el cruce de niveles es menos fuerte que en el Retablo cervantino.

Tanto Cervantes como Quiñones recurren al equivalente de la metalepsis narratológica, es decir que representan la contaminación de un plano hacia otro: se constata el movimiento cuando las creaciones verbales de Chanfalla y Pilonga traspasan la frontera de lo metadramático hacia lo intradramático. Todas las apariciones del retablo funcionan como elementos metalépticos: pasan de un nivel al otro, influyen directamente sobre sus receptores. La particularidad del Retablo de las maravillas radica en que asistimos a una representación dentro de otra, pero

Pilonga es más expeditivo: «Pilonga: Pues ¡ojo alerta, señores!, / que el retablo va saliendo» (Retablo B: vv. 195-196).

16 Sin las otras estructuras teatrales, estaríamos en un caso de metadiégesis: una fábula no escenificada.

17 En el texto de Cervantes, los apartes son escasos. Esta profusión en el Retablo de Quiñones se puede entender por la ausencia de explicaciones sobre el embuste antes de que este se realice. La conversación de Chanfalla y Chirinos es escuchada por el público, que sabe desde entonces que todo es ilusión. En cambio, Pilonga no precisa nada, por lo que se multiplican los apartes para indicar al público extradramático que todo es ficticio. 
sin que se corporicen los elementos de la pieza insertada. Falta uno de los elementos principales de la representación teatral: los personajes metadramáticos. Nos alejamos pues de una fórmula metateatral canónica donde se reproducen todas las instancias dentro de la representación. No obstante, la obra sigue siendo metateatral, justamente por la fuerza verbal de los ingeniosos directores escénicos del plan metadramático. Chanfalla y Chirinos (en Cervantes) y Pilonga (en Quiñones de Benavente) se sirven del poder representativo de la palabra - que hemos señalado con Ingarden - para crear un espacio y unas figuras que no llegan a tener consistencia física, pero sí escénica. Son figuras imaginativas que contribuyen a la realización metateatral. Evidentemente, no se mantendrían en pie sin otros elementos de igual importancia: en lo interno, el contexto mágico preestablecido y la presión social favorecen el poder de la palabra; en lo externo, el uso de los apartes y la corporización efectiva del público intradramático facilitan el buen desarrollo del embuste y su comprensión por parte del espectador extradramático.

La ausencia de corporizacón de esas apariciones mágicas solo es pertinente desde la perspectiva de la visión. Recordemos que existen en nuestro idioma dos adjetivos sensiblemente diferentes: 'visible' y 'visual'. El primero es formado por el participio 'visus' y el sufijo '-ible', de modo que significa «que puede ser visto», y, aferrándonos a la definición del sentido de la vista, esta posibilidad depende de elementos físicos. El segundo adjetivo, 'visual', también tiene como raíz 'visus' pero, esta vez, con el sufijo '-alis' («relativo a»). Vemos pues la diferencia entre un lema que define la capacidad física de distinguir elementos con sus propios ojos, mientras que el otro califica el ver con los ojos de la imaginación, de forma figurada.

Nuestro análisis nos lleva a la reconsideración esencial de lo que es la escena en cuanto a espacio de percepciones. Nos referimos a esta definición como punto de partida: «Il faut et il suffit, pour qu'il y ait espace théâtral, qu'il y ait des hommes unis par la fonction du regard: des regardants et des regardés» (Ubersfeld 1996: 51). Ahora bien, el Retablo de las maravillas es problemático ante todo porque los «regardés» no pueden ser vistos. Sin embargo, hemos señalado que pueden ser visualizados, y esto gracias a la fuerza creadora de la enunciación: «La parole apparaît donc comme un mode de dramatisation extrêmement efficace dans l'art de la mise en scène» (Saminadayar-Perrin 2001: 66). Esta función del verbo se elabora a través de etapas bien delimitadas de la creación de la imagen que hemos destacado con la función representativa del lenguaje y la necesidad de un contexto mágico instaurado por un ingenioso (Rincón, Chanfalla, Chirinos, Pilonga).

Si hemos visto que en Los refranes del viejo celoso estamos todavía en un plan metadramático, el Retablo de las maravillas nos presenta efectivamente una construcción metateatral, pero muy particular. Una de las instancias teatrales duplicadas no es visible: es visual. Y esta producción se lleva a cabo con la ayuda 
de un regidor y de su discurso. Las palabras que emite producen el mismo efecto que lo que sería, en la novelística, el fenómeno de hipotiposis (Rykner 2001: 103):

Délimitée, définie, "cadrée" par les procédés narratifs, la scène s'affirme paradoxalement comme le moment précis où l'image échappe au texte (s'échappe du texte). [...] Instant où le texte "hallucine", elle appelle un regard qu'elle s'attache à faire converger vers le seul point qui lui échappe, celui où le visible s'abîme et se sublime dans le "visuel".

Aunque Rykner se refiera a la teatralización de pasajes narrativos en la prosa, su afirmación de la escena verbal elevada al rango de imagen no excluye el teatro y el metateatro. Como lo señala acertadamente: «La scène ainsi rejetée du côté de l'énonciation échappe au figurable mais retrouve ses racines imaginaires. La parole se transforme en souffle, le visible laisse la place au visuel» (Rykner 2001: 106).

Así pues, si sintetizamos los elementos presentados hasta ahora, podemos precisar la definición de metateatro para aplicarla al plano de la representación metateatral visual. Consiste en la duplicación de elementos dramáticos mediante una mise en abyme, con la particularidad de reproducir uno/varios de estos elementos sin su corporización visible efectiva, sino a través de una imagen visual creada por una situación comunicativa particular —siempre que su validez sea corroborada por el contexto en el que se sitúa.

Otra conclusión resalta en nuestro análisis: existe una diferencia entre los protagonistas de Los refranes y las apariciones del Retablo. Por un lado, los personajes proverbiales (Calaínos, el rey Perico, Quintañona, etc.) que aparecen en el mundo mágico creado por Rincón son metadramáticos porque son escenificados. Sin embargo, permanecen en la esfera onírica. Por otro lado, las apariciones enunciadas por Chanfalla o Pilonga no llegan a ser corporizadas, pero son metateatrales porque pertenecen a la configuración del teatro dentro del teatro. La diferencia entre ambos grupos de protagonistas es aquí estructural. La estructura, en el Reta$b l o$, se antepone a la corporización y, mediante la enunciación, se construye el metateatro. En cambio, en Los refranes hay corporización efectiva pero sin cuadro estructural que remita al universo dramático. Volvemos a ver, por consiguiente, la importancia de la forma y de sus ecos en la representación insertada. Es fundamental este aspecto en cuanto a la construcción de la mise en abyme que supone el metateatro. Sea visible o visual, su existencia se debe siempre a estructuras que recuerdan las de la obra en la que se insertan. Así pues, no se puede analizar el metateatro visual sin estar atento a su formación: el metateatro visual es una variante de la forma original de metateatralidad visible.

Recibido: 22/05/2015

Aceptado: 27/07/2015 


\section{OBRAS CITADAS}

Abel, Lionel (2003). Tragedy and Metatheatre: Essay on Dramatic Form. New York: Holmes \& Meier.

AsENSIO, Eugenio (1971). Itinerario del entremés: desde Lope de Rueda a Quiñones de Benavente, con cinco entremeses inéditos de D. Francisco de Quevedo. Madrid: Gredos.

Bergmann, Hanna (1975). «Los refranes del viejo celoso y otras obras afines». Nueva Revista de Filología Hispánica, xxiv, pp. 376-397 [abreviado Refranes].

CERvantes, Miguel de (1990). «El retablo de las maravillas» [1615]. En Entremeses. Edición de Nicholas Spadaccini. Madrid: Cátedra, pp. 215-236 [abreviado Retablo A].

Cotarelo y Mori, Emilio (2000). Colección de entremeses, loas, bailes, jácaras y mojigangas desde fines del siglo xvi a mediados del xviii. Granada: Editorial Universidad de Granada.

DÄLlENBACH, Lucien (1977). Le récit spéculaire, essai sur la mise en abyme. Paris: Seuil.

FORESTIER, Georges (1981). Le théâtre dans le théâtre sur la scène française du xviie siècle. Genève: Droz.

García BARrientos, José Luis (2007). Cómo se comenta una obra de teatro: ensayo de método. Madrid: Síntesis.

Genette, Gérard (1972). Figures III. París: Seuil.

Herzog, Christophe (2013). Mito, tragedia y metateatro en el teatro español del siglo XX. Lausanne: Sociedad Suiza de Estudios Hispánicos (col. Hispánica Helvética).

Hornby, Richard (1986). Drama, Metadrama and Perception. Lewisburg: Bucknell University Press.

Huerta Calvo, Javier (2001). El teatro breve en la Edad de Oro. Madrid: Laberinto.

- (dir.). Historia del teatro breve en España. Madrid/Frankfurt: Iberoamericana/ Vervuert, 2008.

INGARDEN, Roman (1997). «Las funciones del lenguaje en el teatro». En María del Carmen Bobes Naves (ed.), Teoría del teatro. Madrid: Arco/Libros, pp. 155-165.

MARTínez LóPEZ, María José (1997). El entremés: radiografía de un género. Toulouse: Presses Universitaires du Mirail.

Quevedo y Villegas, Francisco (2005). Los refranes del viejo celoso. En Celsa Carmen García Valdés (ed.), Entremesistas y entremeses barrocos. Madrid: Cátedra, pp. 115117.

Quiñones de Benavente, Luis (2005). El retablo de las maravillas. En Celsa Carmen García Valdés (ed.), Entremesistas y entremeses barrocos. Madrid: Cátedra, pp. 173186 [abreviado Retablo B].

RYKNER, Arnaud (2001). «Du visible au visuel: flux et reflux de la scène». En Marie-Thérèse Mathet (ed.), La scène. Littérature et Arts Visuels. París: L'Harmattan, pp. 103-108.

SAMINADAYAR-PERrIN, Corinne (2001). «Rhétoriques de la scène». En Marie-Thérèse Mathet (ed.), La scène. Littérature et Arts Visuels. París: L’Harmattan, pp. 45-66.

UBERSFELD, Anne (1996). Lire le théâtre, vol. 2. París: Belin. 
Dos entremeses «auditivos» y sus niveles: hacia un metateatro visual

Resumen: El metateatro ha dado lugar a numerosas reflexiones sobre la estructura de una representación. Con sus construcciones particulares, el entremés contribuye al análisis del fenómeno, mediante juegos verbales y estructurales estrechamente relacionados. A través de un comentario sobre dos entremeses en concreto, pretendemos aportar nuevas consideraciones sobre la concepción de un metateatro visual, cuya modalidad auditiva pasa por la fuerza creadora de la palabra.

Palabras claves: entremés, metateatro, niveles, refranes.

Two «auditive» entremeses and their levels: towards a visual metatheatre

ABSTRACT: The metatheatre has led to numerous thoughts on the structure of a representation. With its particular constructions, the entremés contributes to the analysis of the phenomenon, through verbal and structural games, closely connected. With a comment on two entremeses in particular, we intend to bring new considerations on the design of a visual metatheatre whose hearing modality passes across the creative power of the word.

KEYWORDS: entremés, metatheatre, levels, proverbs. 
TERESA DE JESÚS (1515-1582)

Guillermo Serés (Universidad Autónoma de Barcelona)

La imaginación de Santa Teresa: virtudes y desatinos de «la loca de la casa»....... 11

Ana Garriga EsPino (Universidad Autónoma de Madrid)

El desafío editorial de las cartas de Teresa de Jesús.

LeCTURAS REPUBLICANAS DEL QUIJOTE

RAQUEL ArIas (Universidad Autónoma de Madrid)

León Felipe alista a don Quijote en el bando republicano. 57

MANUEl LóPez ForJas (Universidad Autónoma de Madrid)

El Quijote y la realidad viva de las Españas: la visión histórica

de Pedro Bosch-Gimpera.

CArmen Madorrán Ayerra (Universidad Autónoma de Madrid)

El Quijote como utopía necesaria: la mirada de Adolfo Sánchez Vázquez 85

\section{OTROS TEMAS}

SònIA BoADAS (Universitat Autònoma de Barcelona)

Libros y librerías: la recepción de Commynes en España 101

Lucila Lobato Osorio (Universidad Nacional Autónoma de México)

La noticia de la muerte de Policisne de Boecia: expresiones de dolor en un libro inconcluso.

María Gutiérrez Padilla (Universidad Nacional Autónoma de México)

La escenografía en el teatro caballeresco 131

ADRIÁn FERnÁNDEZ (Université de Fribourg)

Dos entremeses «auditivos» y sus niveles: hacia un metateatro visual. 145

David González de la Higuera Garrido (Universidad Complutense de Madrid) La visión premonitoria de Alonso en El caballero de Olmedo:

otra recuperación de lo popular

Esther Fernández LóPEz (UNED)

Perseo en la comedia tardobarroca: Ignacio Ferrera y Pasqual 169

Manuel Piqueras Flores (Universidad Autónoma de Madrid)

De La hija de Celestina $a$ La ingeniosa Elena: estructura narrativa, género literario e interpolación 
Dagoberto CÁceres Agullar (Western University Canada)

Realismo incesante: desde Celestina hacia su recepción 201

TeXTOS INÉDITOS

Davinia Rodríguez Ortega (Universidad Pública de Navarra)

Auto sacramental del Juego del Hombre, de Luis Mejía de la Cerda:

edición crítica 


\section{EDAD DE ORO}

Revista de Filología Hispánica XXXIV

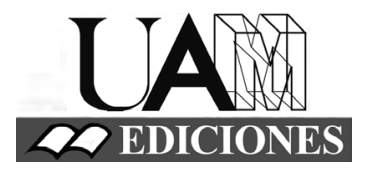




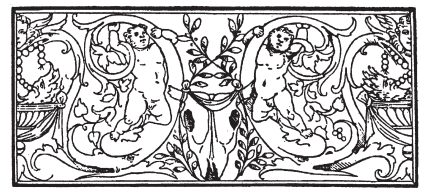

\section{Edad de Oro. Revista de Filología Hispánica}

ISSN: 0212-0429

Dirección:

Teodosio Fernández

Secretaría y edición:

José Ramón Trujillo

Comité científico internacional:

Carlos Alvar (Univ. de Ginebra)

Ignacio Arellano (Univ. de Navarra)

Javier Blasco (Univ. de Valladolid)

Alberto Blecua (UAB)

Jean Canavaggio (Univ. de París X)

Laura Dolfi (Univ. de Turín)

Aurora Egido (Univ. de Zaragoza)

Víctor García de la Concha (RAE)

Luciano García Lorenzo (CSIC)

Joaquín González Cuenca (Univ. de Castilla-

La Mancha)

Agustín de La Granja (Univ. de Granada)

Begoña López Bueno (Univ. de Sevilla)

Michel Moner (Univ. de Toulouse III)

Joan Oleza (Univ. de Valencia)

Alfonso Rey (Univ. de Santiago)

Lina Rodríguez Cacho (Univ. de Salamanca)

Leonardo Romero Tobar (Univ. de Zaragoza)

Aldo Ruffinatto (Univ. de Turín)

Lía Schwartz (City University of New York)
Redacción y admisión de originales:

Teodosio Fernández

Edad de Oro

Departamento de Filología Española

Universidad Autónoma de Madrid

28049 Madrid (España)

Tfno.: +0034914974090

correo: teodosio.fernandez@uam.es

Distribución, suscripción y venta:

Servicio de Publicaciones de la UAM

Universidad Autónoma de Madrid

28049 Madrid (España)

Intercambio de publicaciones:

Biblioteca de la Facultad de Filosofía y

Letras (UAM)

Universidad Autónoma de Madrid

28049 Madrid (España)

Han colaborado en este volumen:

Departamento de Filología Española (UAM)

Facultad de Filosofia y Letras (UAM)

Edad de Oro se recoge, entre otras, en las siguientes bases de datos: SCOPUS, MLA Database, HLAS, Latindex, PIO-Periodical Content Index, ISOC, Dialnet, MIAR, ERIH, DICE, Sumaris CBUC, Ulrich's. Se encuentra evaluada en CIRC: A; INRECH; MIAR difusión ICDS live: 9.977; SCImago Journal \& Country Rank: H Index 2, SJR 0,101, Q4; RESH índice de impacto: 0.041; ERIH: A INT1; Carhus Plus+ 2014: C. 